\title{
Patients with celiac disease are at high risk of developing metabolic syndrome and fatty liver
}

\author{
Ashish Agarwal, Alka Singh, Wajiha Mehtab, Vipin Gupta, Ashish Chauhan, Mahendra Singh Rajput, Namrata Singh, \\ Vineet Ahuja, Govind K. Makharia \\ Department of Gastroenterology and Human Nutrition, All India Institute of Medical Sciences, New Delhi, India
}

Background/Aims: Gluten-free diet has an excess of fats and simple sugars and puts patients with celiac disease at risk of metabolic complications including metabolic syndrome and fatty liver. We assessed prevalence of metabolic syndrome and fatty liver in two cohorts of celiac disease. Methods: Study was done in 2 groups. In group 1, 54 treatment naïve patients with celiac disease were recruited. Of them, 44 returned after 1-year of gluten-free diet and were reassessed. In group 2, 130 celiac disease patients on gluten-free diet for $\geq 1$ year were recruited. All patients were assessed for anthropometric and metabolic parameters and fatty liver. Metabolic syndrome was defined as per consensus definition for Asian Indians. Fatty liver was defined as controlled attenuation parameter value $>263$ decibels by FibroScan. Results: In group 1, of 44 treatment naïve patients with celiac disease, metabolic syndrome was present in 5 patients (11.4\%) at baseline and $9(18.2 \%)$ after 1 year of gluten-free diet. Patients having fatty liver increased from 6 patients (14.3\%) at baseline to $13(29.5 \%)$ after lyear of gluten-free diet $(P=0.002)$. In group 2, of 130 patients with celiac disease on gluten-free diet for a median duration of 4 years, 30 out of 114 (26.3\%) and 30 out of 130 patients (23\%) had metabolic syndrome and fatty liver, respectively. Conclusions: Patients with celiac disease are at high risk of developing metabolic syndrome and fatty liver, which increases further with gluten-free diet. These patients should be assessed for nutritional and metabolic features and counseled about balanced diet and physical activity regularly. (Intest Res 2021;19:106-114)

Key Words: Diabetes mellitus; Hyperlipidemia; Body mass index; Obesity; Fatty liver

\section{INTRODUCTION}

Celiac disease (CeD) is usually considered to lead to undernutrition and low weight both in children and adults; in recent times, however, many patients with $\mathrm{CeD}$ are found to be not only overweight but some even being obese. ${ }^{1}$ In a retrospective study, we observed that $54.8 \%$ of treatment naïve patients with CeD had their body mass index (BMI) within normal limits, $8.1 \%$ of them, however, were either overweight or

Received October 22, 2019. Revised December 30, 2019.

Accepted January 31, 2020.

Correspondence to Govind K. Makharia, Department of Gastroenterology

and Human Nutrition, All India Institute of Medical Sciences, Ansari Nagar,

New Delhi 110029, India. Tel: +91-11-26546546, Fax: +91-11-26588091,

E-mail: govindmakharia@gmail.com obese. ${ }^{1}$ Numerous other studies have made similar observations and up to $44 \%$ of the patients were found to be overweight or obese at the time of diagnosis of $\mathrm{CeD} .^{2,3}$ Furthermore, many studies have uniformly shown that underweight patients at the time of diagnosis tend to gain weight on glutenfree diet (GFD).$^{4-6}$ Contradictory to that while $22 \%$ to $82 \%$ of overweight and obese patients gain weight on a $\mathrm{GFD} ;{ }^{4,7}$ some of the overweight and obese patients with $\mathrm{CeD}$ lose weight on $\mathrm{GFD}^{6,8}$ As described above, many studies have looked into the effect of a GFD on BMI but the association between CeD and metabolic syndrome has not been explored in much detail. In a recent prospective study, Tortora et al. ${ }^{9}$ reported an increase in the prevalence of metabolic syndrome from $2 \%$ at the time of diagnosis to $30 \%$ after 12 months of GFD. Although there is emerging evidence that a sizeable proportion of patients with 
CeD gain weight and end up developing metabolic syndrome, the pathogenesis of this condition is not very clear. Processed GFD is considered to be nutritionally imbalanced that lead to a higher intake of carbohydrates with a higher glycemic index. ${ }^{10}$ Furthermore, high quantity of saturated fat used in preparing GFD processed food to make them palatable, also add to higher calorie intake. ${ }^{10}$ Moreover, a phenomenon of hyperabsorption have been described after the restoration of intestinal mucosal function with GFD in patients with $\mathrm{CeD} .{ }^{10} \mathrm{~A}$ differential secretion pattern of brain-gut axis hormones has also been described in patients with both untreated and treated CeD that may underlie weight gain and development of the metabolic syndrome. ${ }^{10,11}$

In the background of obesity and metabolic syndrome, many patients develop nonalcoholic fatty liver disease (NAFLD). Fatty liver, if untreated, can lead to cirrhosis in up to $3 \%$ patients. ${ }^{12}$ There are studies to suggest that patients with $\mathrm{CeD}$ are at 3-fold higher risk of developing NAFLD. ${ }^{13-18}$ Furthermore, patients with $\mathrm{CeD}$ are at a higher risk of cardiovascular diseases (hazard ratio, 1.10; 95\% confidence interval [CI], 1.03-1.28) and stroke (odds ratio, 1.11; 95\% CI, 1.02-1.20). ${ }^{19}$

Since there is a limited data globally and none from Asia on the prevalence of metabolic syndrome and fatty liver disease in patients with $\mathrm{CeD}$, we conducted a study to assess the prevalence of metabolic syndrome in treatment naïve patients with CeD before and after 1 year of GFD prospectively and in another cohort of patients with CeD who were on GFD for at least 1 year.

\section{METHODS}

This prospective study was conducted at the Celiac Disease Clinic, All India Institute of Medical Sciences, New Delhi. The study protocol was approved by the Institutional Ethics Committee (approval No. IECPG-527/26.10.2016) and written informed consent was taken from each participant. The study protocol conforms to the ethical guidelines of the 1975 Declaration of Helsinki as reflected in a priori approval by the institution's human research committee.

The study was conducted in 2 groups. In group 1, treatment naïve biopsy-proven adult patients with $\mathrm{CeD}$ presenting to the clinic between November 2016 and October 2017 were assessed for metabolic syndrome and fatty liver at the baseline and then they were reassessed after 1 year of GFD. In group 2, we assessed patients with CeD who were already on GFD for more than 1 year for the presence of metabolic syndrome and fatty liver.

Pregnant patients, patients consuming more than 2 standard alcoholic drinks per day, smokers, patients with preexisting diagnosed chronic liver disease, patients with a co-morbid illness such as cardiac diseases, renal diseases, pulmonary diseases, uncontrolled hypothyroidism, malignancy, untreated infection, and uncontrolled type I diabetes were excluded. The diagnosis of $\mathrm{CeD}$ was made based on standard criteria, i.e. a positive anti-tissue transglutaminase and/or anti-endomysium antibody and presence of villous abnormality of modified Marsh grade 2 and above. ${ }^{20}$

\section{Study Parameters}

All the patients in both the groups underwent assessment for the demographic and clinical parameters including ethnicity, personal or family history of prior hyperlipidemia, hypertension, diabetes, peripheral vascular disease, coronary artery disease, NAFLD or obstructive sleep apnea. They were also assessed for blood pressure $(\mathrm{mmHg})$, height $(\mathrm{cm})$, weight $(\mathrm{kg})$, BMI $\left(\mathrm{kg} / \mathrm{m}^{2}\right)$, waist and hip circumference (as per WHO STEPwise approach to surveillance protocol), ${ }^{21}$ and waist-hip ratio. Baseline laboratory work included complete hemogram, liver function tests, renal function tests, fasting serum glucose, fasting lipid panel and IgA anti-tissue transglutaminase antibodies. These clinical and laboratory parameters were obtained again at a follow-up of 1 year on GFD in the participants included in group 1 .

\section{Measurement of Liver Stiffness and Controlled Attenuation Parameter}

Liver stiffness measurement and controlled attenuation parameter (CAP) measurement were performed on a FibroScan touch 502 (Echosens, Paris, France) as per the standard recommendations. All measurements were performed by a single operator and measurements were done in fasting state in morning hours. The operator of FibroScan was blinded to the clinical and biological data of the patients. FibroScan was done at baseline and after 1 year of follow-up in the participants of group 1 and at the time of recruitment in group 2 .

\section{Body Composition Analyses}

Body composition was assessed using bioelectrical impedance analysis using a Tanita TBF-215 leg-to-leg portable impedance analyzer (Tanita, Tokyo, Japan). The body weight and impedance were measured from which the fat mass, percentage fat and fat-free mass were calculated. The fat mass was 
computed as the difference between body weight and fat-free mass. Fat mass index (FMI) was calculated as fat mass/ height ${ }^{2}$. Height was measured using the built-in height rod in the instrument. For all patients, $0.5 \mathrm{~kg}$ was deducted to account for their clothes. All measurements were made empty stomach after 12 hours of overnight fast, without any intake of liquids. Three repeat measurements were recorded and the mean value was taken as final.

\section{1) Treatment of $\mathrm{CeD}$}

All treatment naïve patients were counseled by an expert and dedicated dietician (W.M.) and all of them were followed at 3 months interval for reconciling and assessment of adherence. Adherence was assessed based on detailed dietary history by the dietician and was graded as follows: (1) excellent: participant ate gluten once per 6 months; (2) good: participant ate gluten 0-1 times per month; (3) poor: participant ate gluten 2-3 times per month, participant ate gluten greater than two times per week or participant does not follow GFD.

\section{Definition of Outcome Measures}

Consensus definition for Asian Indians ${ }^{22}$ was used for the diagnosis of metabolic syndrome. It includes the following 5 parameters: (1) abdominal obesity measured as waist circumference ( $>90 \mathrm{~cm}$ for males and $>80 \mathrm{~cm}$ for females); (2) hypertriglyceridemia (serum triglycerides level $>150 \mathrm{mg} / \mathrm{dL}$ ); (3) low levels of serum high density lipoprotein (HDL) cholesterol ( $<40 \mathrm{mg} / \mathrm{dL}$ for males and $<50 \mathrm{mg} / \mathrm{dL}$ for females); (4) hypertension (blood pressure > 130/85 $\mathrm{mmHg}$ ); and (5) fasting hyperglycemia (fasting blood sugar [FBS] $>100 \mathrm{mg} / \mathrm{dL}$ ). All those patients satisfying at least 3 of 5 criteria were classified as having metabolic syndrome.

\section{1) Fatty Liver}

Patients having a CAP value of more than 263 decibels, as determined by FibroScan technique, were classified as having fatty liver. The severity of fatty liver was defined as follows: grade I: CAP 263-286.9 dB; grade II: CAP 287-295.9 dB; grade III: $\mathrm{CAP} \geq 296 \mathrm{~dB}^{23}$

\section{2) Obesity}

BMI was calculated as weight $/$ height ${ }^{2}\left(\mathrm{~kg} / \mathrm{m}^{2}\right)$ and was graded as per the BMI classification suggested by the Consensus Statement for Asian Indians as follows: ${ }^{22}$ underweight: BMI $<18.5 \mathrm{~kg} / \mathrm{m}^{2}$; normal: BMI $18.5-22.9 \mathrm{~kg} / \mathrm{m}^{2}$; overweight: BMI $23-24.9 \mathrm{~kg} / \mathrm{m}^{2}$; and obese: $\mathrm{BMI} \geq 25 \mathrm{~kg} / \mathrm{m}^{2}$.

\section{Statistical Analysis}

Statistical analysis was performed using SPSS version 13.0 (SPSS Inc., Chicago, IL, USA). Continuous variables were expressed as mean \pm standard deviation or median (range) as appropriate. Categorical variables were compared by chisquare test or Fisher exact test as appropriate. Continuous variables were compared by Student $t$-test or Mann-Whitney test as appropriate.

\section{RESULTS}

\section{Comparison of Anthropometric and Metabolic Parameters of Patients before and after 1 Year of GFD: Group 1}

In this study, we screened 86 consecutive patients with $\mathrm{CeD}$ for inclusion in the study, of which 54 treatment naïve CeD patients were included and they underwent baseline assessment and were started on GFD under the care of a nutritionist. Of them, 10 patients were lost to follow-up and 44 patients were reassessed after 1 year of GFD (Fig. 1A). Of 54 treatment naïve patients, 9 patients (16.6\%) were overweight or obese, 13 (24.1\%) had fatty liver and 5 (11.1\%) had evidence of metabolic syndrome at the baseline.

\section{1) Changes in BMI and Obesity}

Though there was no significant increase in the height $(P=0.3)$ of the patients, there was a significant rise in the body weight after 1 year of GFD (before $49.0 \pm 13.7 \mathrm{~kg}$ vs. after $53.2 \pm 13.3 \mathrm{~kg}$; $P<0.001)$ thus resulting in a significant increase in BMI $(P=0.003)$. The proportion of overweight and obese patients increased from $13.6 \%$ at the baseline to $25 \%$ after 1 year of GFD (Fig. 2A). This was also associated with an increase in the mean waist circumference (before $76.9 \pm 10.9 \mathrm{~cm}$ vs. after $80.1 \pm 12.5 \mathrm{~cm}$; $P=0.003$ ) and the mean hip circumference (before 84.6 \pm 7.9 cm vs. $88.0 \pm 8.7 \mathrm{~cm}$ after; $P<0.001)$. On body composition analysis, in comparison to the baseline, there was a significant increase in the median body fat percentage (before 10\% [interquartile range (IQR), 2.5-31] vs. after 12\% [IQR, 1.8-37]; $P=0.001$ ) and FMI (before $1.8 \mathrm{~kg} / \mathrm{m}^{2}$ [IQR, 0.44-9.1] vs. after $2.4 \mathrm{~kg} / \mathrm{m}^{2}$ [IQR, $\left.0.3-10.5\right] ; P=0.003$ ) after 1 year of GFD (Table 1).

\section{2) Metabolic Syndrome in Treatment Naïve Patients with CeD and 1 Year after GFD}

Nine of 44 patients (18.2\%) had evidence of metabolic syndrome after 1 year of GFD, compared to 5 of 44 patients (11.4\%) before starting GFD, suggesting a rise in the prevalence of 
A

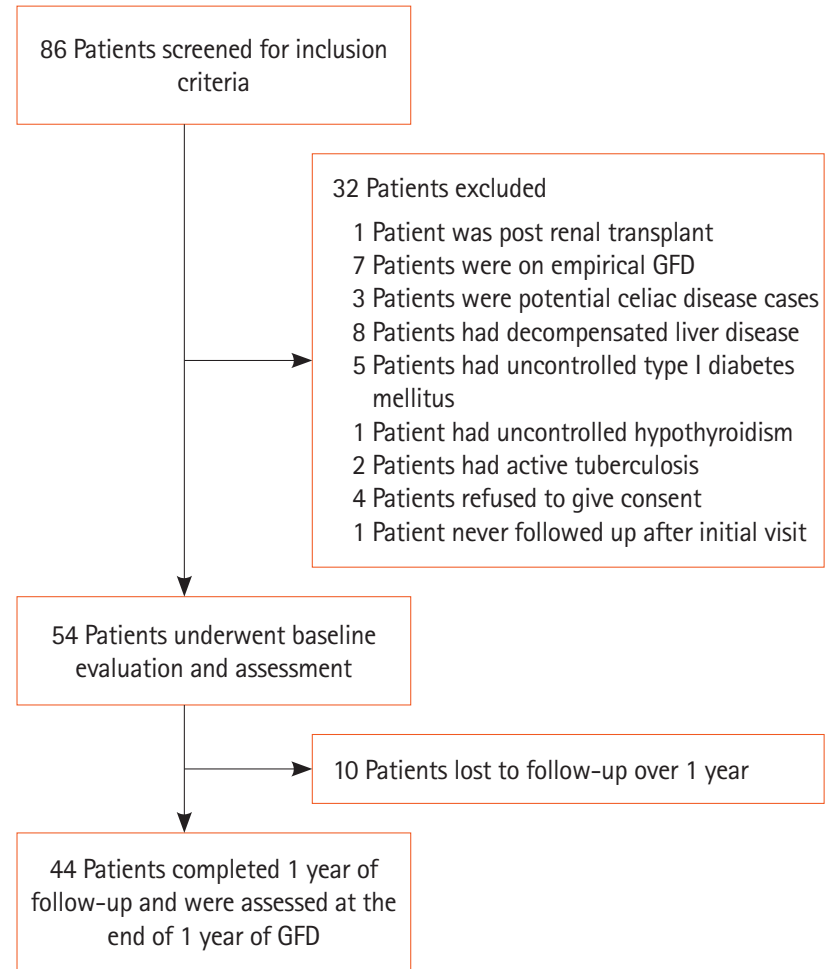

B

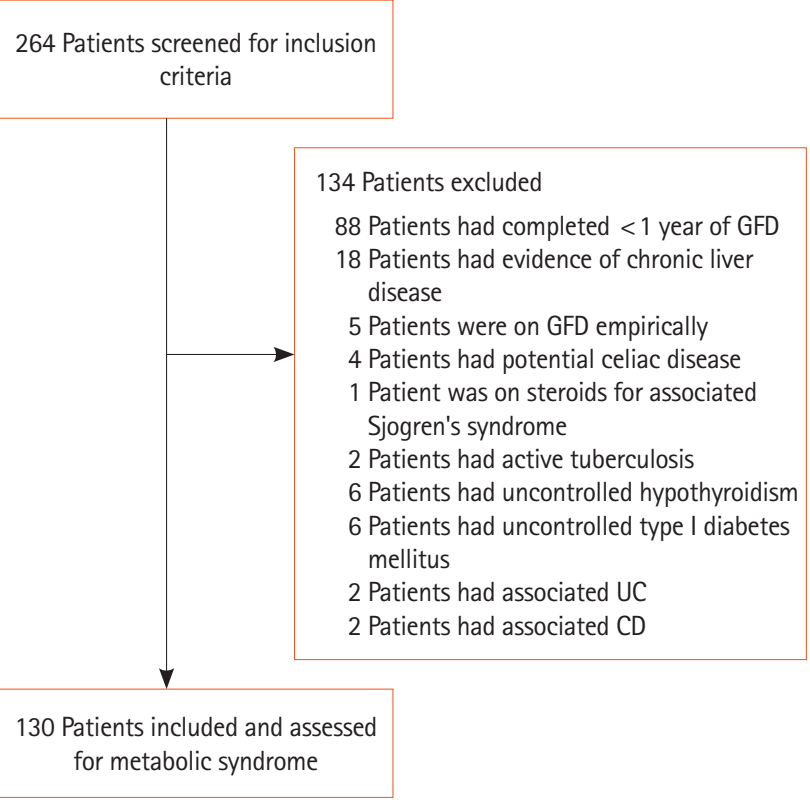

Fig. 1. (A) Flowchart showing enrolment of newly diagnosed celiac disease patients and follow-up. (B) Flowchart showing enrolment of patients with celiac disease on gluten-free diet (GFD) for more than 1 year. UC, ulcerative colitis; CD, Crohn's disease.
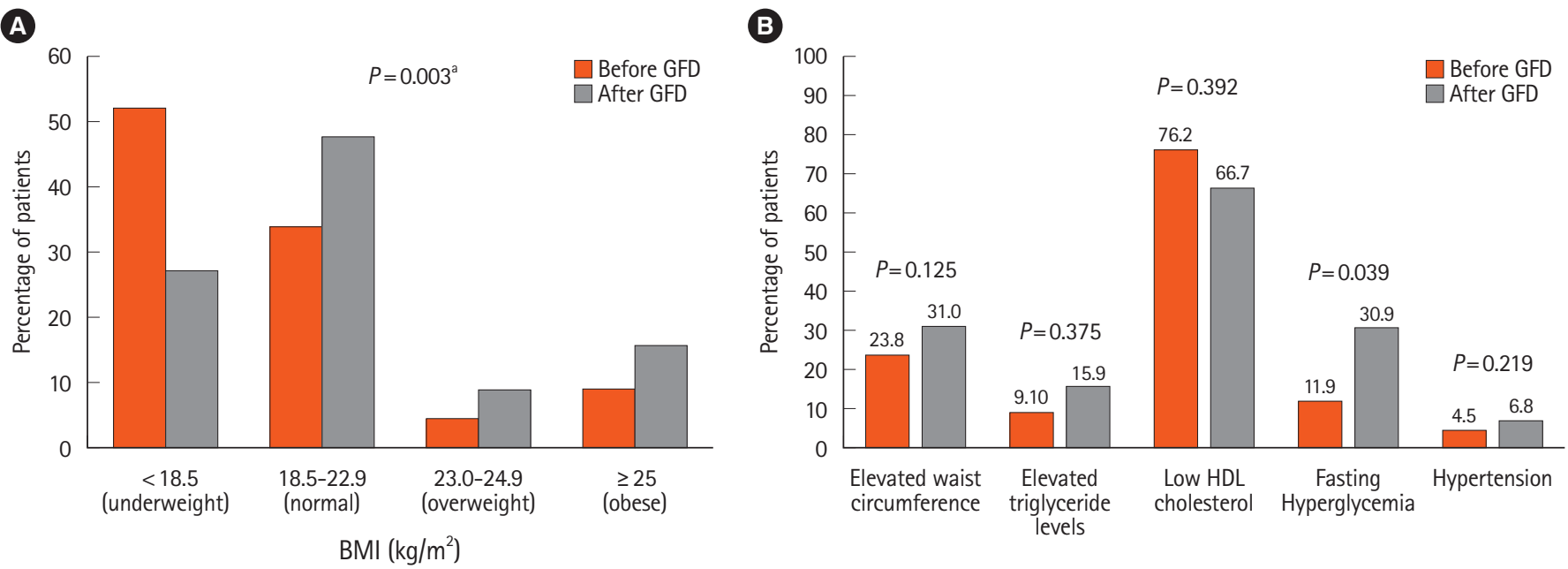

Fig. 2. (A) Comparison of body mass index (BMI) before and after gluten-free diet (GFD). (B) Individual criteria of metabolic syndrome before and after 1 year of GFD. ${ }^{a}$ P-value for the BMI distribution before and after GFD.

metabolic syndrome after just 1 year of GFD (Table 2). Of the 5 patients with metabolic syndrome before initiation of GFD, 4 continued to have metabolic syndrome. One patient ceased to satisfy the criteria for metabolic syndrome, mainly because of improvement in the value of HDL, though he continued to have elevated FBS level and high waist circumference. Five new patients developed metabolic syndrome at 1 year of GFD.

Among the individual parameters of the metabolic syndrome, the number of patients having hyperglycemia increased from $5(11.9 \%)$ to $13(30.9 \%)(P=0.039)$ and hypertri- 
Table 1. Comparison of Demographic, Clinical, Biochemical, Anthropometric and Metabolic Parameters of Patients before and after 1 Year of GFD and Patients on Long-term GFD

\begin{tabular}{|c|c|c|c|c|}
\hline Characteristic & $\begin{array}{l}\text { Before GFD } \\
(n=44)\end{array}$ & $\begin{array}{l}\text { After GFD } \\
(n=44)\end{array}$ & $P$-value ${ }^{a}$ & $\begin{array}{l}\text { Patients on long-term GFD } \\
\qquad(n=130)\end{array}$ \\
\hline Sex & & & - & \\
\hline Male & $18(41.0)$ & $18(41.0)$ & & $53(40.8)$ \\
\hline Female & $26(59.0)$ & $26(59.0)$ & & $77(59.2)$ \\
\hline Age $(y r)$ & $29.5 \pm 11.3$ & - & - & $33.0 \pm 13.1$ \\
\hline Hemoglobin (g/dL) & $10.4 \pm 2.6$ & $12.4 \pm 1.8$ & $<0.001$ & $12.1 \pm 1.8$ \\
\hline Hemoglobin categories (g/dL) & & & $<0.001$ & \\
\hline$<8$ & $10(23.3)$ & 0 & & $2(1.6)$ \\
\hline $8-12$ & $17(39.5)$ & $19(43.2)$ & & $59(45.4)$ \\
\hline$>12$ & $16(37.2)$ & $25(56.8)$ & & $67(51.5)$ \\
\hline Corpuscular volume (fL/cell) & $77.2 \pm 10.6$ & $81.0 \pm 7.0$ & 0.009 & $83.4 \pm 8.8$ \\
\hline Corpuscular hemoglobin (pg/cell) & $25.2 \pm 4.3$ & $28.2 \pm 10.3$ & 0.080 & $27.2 \pm 2.9$ \\
\hline Corpuscular hemoglobin concentration (g/dL) & $30.8 \pm 1.7$ & $31.4 \pm 2.1$ & 0.014 & $31.5 \pm 1.8$ \\
\hline AST (U/L) & $32.8 \pm 16.0$ & $31.7 \pm 14.8$ & 0.420 & $28.5(11.0-83.0)$ \\
\hline ALT (U/L) & $30.9 \pm 13.8$ & $30.9 \pm 19.1$ & 0.974 & $28.5(8.0-73.0)$ \\
\hline Transaminitis (more than 1.5 times elevated) & $4 / 42(9.5)$ & $3 / 44(6.8)$ & 0.240 & $10 / 130(7.7)$ \\
\hline IgAtTG elevation (folds rise) & $9.2(1.5-40.5)$ & $2.1(0.1-14.2)$ & $<0.001$ & $0.9(0.1-55.3)$ \\
\hline IgAtTG more than one folds rise & - & $30 / 44(68.2)$ & - & $56 / 125(44.8)$ \\
\hline Compliance with GFD & - & & - & \\
\hline Excellent & & $23(52.3)$ & & $90(69.8)$ \\
\hline Good & & $14(31.8)$ & & $27(20.9)$ \\
\hline Poor & & $1(2.3)$ & & $9(6.9)$ \\
\hline Very poor & & $6(11.1)$ & & $3(2.3)$ \\
\hline Height $(\mathrm{cm})$ & $158.7 \pm 11.0$ & $159.0 \pm 10.7$ & 0.300 & $156.7 \pm 21.7$ \\
\hline Weight (kg) & $49.0 \pm 13.7$ & $53.2 \pm 13.3$ & $<0.001$ & $57.1 \pm 12.8$ \\
\hline $\mathrm{BMI}\left(\mathrm{kg} / \mathrm{m}^{2}\right)$ & $19.3 \pm 4.2$ & $20.9 \pm 4.1$ & $<0.001$ & $22.5 \pm 4.3$ \\
\hline BMI categories $\left(\mathrm{kg} / \mathrm{m}^{2}\right)$ & & & 0.003 & \\
\hline$<18.5$ & $23(52.3)$ & $12(27.3)$ & & 25 (19.2) \\
\hline $18.5-22.9$ & $15(34.1)$ & $21(47.7)$ & & $54(41.5)$ \\
\hline $23.0-24.9$ & $2(4.54)$ & $4(9.1)$ & & $18(13.8)$ \\
\hline$>25.0$ & $4(9.1)$ & 7 (15.9) & & $33(25.4)$ \\
\hline Waist circumference (cm) & $76.9 \pm 10.9$ & $80.1 \pm 12.5$ & 0.003 & $82.1 \pm 10.6$ \\
\hline Elevated waist circumference & & & 0.125 & \\
\hline Male $>90 \mathrm{~cm}$ & $3(16.7)$ & $3(16.7)$ & & $11(20.8)$ \\
\hline Female $>80 \mathrm{~cm}$ & 7 (26.9) & $11(42.3)$ & & $44(57.1)$ \\
\hline Hip circumference (cm) & $84.6 \pm 7.9$ & $88.0 \pm 8.7$ & $<0.001$ & $90.4 \pm 9.2$ \\
\hline Body fat $\%$ & $10.0(2.5-31.0)$ & $12.0(1.8-37.0)$ & 0.001 & $18.0(1.1-40.0)$ \\
\hline Elevated body fat percentage & & & 0.713 & \\
\hline Male $>25 \%$ & $2(11.1)$ & $3(16.7)$ & & $6(11.3)$ \\
\hline Female $>30 \%$ & $1(3.8)$ & $2(7.7)$ & & $19(24.7)$ \\
\hline Fat mass index $\left(\mathrm{kg} / \mathrm{m}^{2}\right)$ & $1.8(0.4-9.1)$ & $2.4(0.3-10.5)$ & 0.003 & $3.8(0.2-18.7)$ \\
\hline
\end{tabular}


Table 1. Continued

\begin{tabular}{|c|c|c|c|c|}
\hline Characteristic & $\begin{array}{l}\text { Before GFD } \\
\quad(n=44)\end{array}$ & $\begin{array}{l}\text { After GFD } \\
(n=44)\end{array}$ & $P$-value ${ }^{\text {a }}$ & $\begin{array}{l}\text { Patients on long-term GFD } \\
\qquad(n=130)\end{array}$ \\
\hline Elevated fat mass index $\left(\mathrm{kg} / \mathrm{m}^{2}\right)$ & & & 0.713 & \\
\hline Male $>7$ & $2(11.1)$ & $3(16.7)$ & & $6(11.3)$ \\
\hline Female $>7.9$ & $1(3.8)$ & $2(7.7)$ & & $19(24.7)$ \\
\hline Fasting sugar level (mg/dL) & $91.8 \pm 8.5$ & $93.5 \pm 9.1$ & 0.226 & $94.9 \pm 10.7$ \\
\hline Fasting sugar level > $100 \mathrm{mg} / \mathrm{dL}$ & $5 / 42(11.9)$ & $13 / 42$ (31.0) & 0.039 & $41 / 119$ (34.5) \\
\hline Total cholesterol (mg/dL) & $145.4 \pm 38.7$ & $158.0 \pm 35.8$ & 0.002 & $166.7 \pm 39.0$ \\
\hline $\mathrm{HDL}(\mathrm{mg} / \mathrm{dL})$ & $39.5 \pm 10.3$ & $42.8 \pm 8.7$ & 0.058 & $44.8 \pm 9.8$ \\
\hline Low HDL & & & 0.392 & \\
\hline Male (<40 mg/dL) & $10(55.6)$ & 6 (33.3) & & $15(28.3)$ \\
\hline Female $(<50 \mathrm{mg} / \mathrm{dL})$ & $22 / 25(88.0)$ & $22(84.6)$ & & $46 / 74(62.1)$ \\
\hline $\operatorname{LDL}(\mathrm{mg} / \mathrm{dL})$ & $88.6 \pm 28.4$ & $97.0 \pm 24.0$ & 0.001 & $108.7 \pm 33.4$ \\
\hline $\operatorname{VLDL}(\mathrm{mg} / \mathrm{dL})$ & $13(6-34)$ & $15(10-32)$ & 0.159 & $14(7-42)$ \\
\hline Triglyceride (mg/dL) & $83(38-360)$ & $97(53-436)$ & 0.014 & $105.4 \pm 48.9$ \\
\hline Triglyceride $>150 \mathrm{mg} / \mathrm{dL}$ & $4(9.1)$ & $7(15.9)$ & 0.375 & $16 / 121(13.2)$ \\
\hline Hypertension & $2(4.5)$ & $3(6.8)$ & 1.000 & $6 / 130(4.6)$ \\
\hline LSM (kPa) & $5.1 \pm 1.9$ & $4.8 \pm 1.8$ & 0.098 & $4.9 \pm 1.2$ \\
\hline $\mathrm{CAP}(\mathrm{dB})$ & $213.5 \pm 46.9$ & $230.8 \pm 50.1$ & 0.001 & $226.7 \pm 50.2$ \\
\hline CAP categories (dB) & & & 0.002 & \\
\hline$<263$ (no NAFLD) & $36 / 42(85.7)$ & $31(70.5)$ & & $100(76.9)$ \\
\hline$\geq 263$ (NAFLD) & $6 / 42(14.3)$ & $13(29.5)$ & & $30(23.1)$ \\
\hline 263.0-286.9 (grade I) & $3 / 42(7.1)$ & $5(11.4)$ & & $15(11.5)$ \\
\hline 287.0-295.5 (grade II) & $2 / 42(4.8)$ & 0 & & $5(3.8)$ \\
\hline$\geq 296.0$ (grade III) & $1 / 42(2.4)$ & $8(18.2)$ & & $10(7.7)$ \\
\hline
\end{tabular}

Values are presented as number (\%), mean $\pm \mathrm{SD}$, or median (range).

${ }^{a} P$-value for the difference in values before gluten-free diet (GFD) and after 1 year of GFD.

GFD, gluten-free diet; AST, aspartate aminotransferase; ALT, alanine aminotransferase; IgAtTG, IgA anti-tissue transglutaminase antibody; BMI, body mass index; HDL, high density lipoprotein; LDL, low density lipoprotein; VLDL, very low-density lipoprotein; LSM, liver stiffness measurement; CAP, controlled attenuation parameter; NAFLD, nonalcoholic fatty liver disease; SD, standard deviation.

Table 2. Individual Criteria for Metabolic Syndrome Satisfied before and after 1 Year of GFD and in Patients on Long-term GFD

\begin{tabular}{|c|c|c|c|c|}
\hline \multirow{2}{*}{ Asian Indian Consensus criteria } & \multicolumn{3}{|c|}{ Group 1} & \multirow{2}{*}{$\begin{array}{c}\text { Group } 2 \\
\text { Patients on long-term GFD }\end{array}$} \\
\hline & Before GFD & After 1 year of GFD & $P$-value ${ }^{\text {a }}$ & \\
\hline Abdominal obesity, assessed as waist circumference & & & 0.125 & \\
\hline Male $>90 \mathrm{~cm}$ & $3 / 18(16.7)$ & $3 / 18(16.7)$ & & $11 / 49(22.4)$ \\
\hline Female $>80 \mathrm{~cm}$ & $7 / 26(26.9)$ & $11 / 26(42.3)$ & & $40 / 65(61.5)$ \\
\hline Triglycerides > $150 \mathrm{mg} / \mathrm{dL}$ & $4 / 44(9.1)$ & $7 / 44(15.9)$ & 0.375 & 16/114 (14.0) \\
\hline HDL cholesterol & & & 0.392 & \\
\hline Male $<40 \mathrm{mg} / \mathrm{dL}$ & 10/18 (55.6) & 6/18 (33.3) & & $15 / 49(30.6)$ \\
\hline Female $<50 \mathrm{mg} / \mathrm{dL}$ & $22 / 25(88.0)$ & $22 / 26(84.6)$ & & $43 / 65(66.2)$ \\
\hline Blood pressure $>130 / 85 \mathrm{mmHg}$ & $2 / 44(4.5)$ & $3 / 44(6.8)$ & 1.000 & 6/114 (5.3) \\
\hline Fasting blood sugar $\geq 100 \mathrm{mg} / \mathrm{dL}$ & $5 / 44(11.9)$ & $13 / 44(30.9)$ & 0.039 & 40/114 (35.1) \\
\hline$\geq 3$ Criteria satisfied & $5 / 44(11.4)$ & 9/44 (18.2) & 0.219 & 30/114 (26.3) \\
\hline
\end{tabular}

Value are presented as number/number (\%).

${ }^{a} P$-value for the difference in values before gluten-free diet (GFD) and after 1 year of GFD.

$\mathrm{HDL}$, high density lipoprotein. 
glyceridemia from 4 (9.1\%) to $7(15.9 \%)(P=0.375)$. There was an increase in the patients with elevated waist circumference (before $22.7 \%$ vs. after $31.8 \% ; P=0.125$ ) and 1 patient developed hypertension after starting GFD. Though a slight decrease in the proportion of patients with low HDL levels was noted (before $74.4 \%$ vs. after $63.6 \% ; P=0.392$ ), the change was mainly in male patients (Fig. 2B).

\section{3) Fatty Liver}

While there was no significant difference in the liver stiffness $(P=0.098)$, there however was a significant increase in the mean CAP values from $213.5 \pm 46.9 \mathrm{~dB}$ to $230.8 \pm 50.1 \mathrm{~dB}(P=0.001)$ after 1 year of GFD. The proportion of patients having fatty liver increased from 6 patients (14.3\%) at baseline to 13 patients $(29.5 \%)$ after 1 year of GFD $(P<0.002)$. Furthermore, there was an increase in the proportion of patients having a more severe grade of fatty liver with 8 patients $(18.2 \%)$ patients having grade III fatty liver after 1 year of GFD compared to 1 patient $(2.4 \%)$ at baseline.

\section{Anthropometric and Metabolic Parameters of Patients with CeD on GFD for More Than 1 Years: Group 2}

For the retrospective study, 264 patients with $\mathrm{CeD}$ who were on GFD for more than 1 year were screened and of them, 130 patients who met the inclusion and exclusion criteria were included. They underwent evaluation for metabolic syndrome and fatty liver (Fig. 1B).

\section{1) BMI and Obesity}

Mean BMI was $22.5 \pm 4.3 \mathrm{~kg} / \mathrm{m}^{2}$ with 25 patients (19.2\%) being underweight, 54 patients (41.5\%) with BMI within normal range and 51 patients (39\%) in overweight (13.8\%) and obese (25.4\%) category. On body composition analyses, median body fat percentage was $18.0 \%$ (range, $1.1 \%-40.0 \%$ ) and both body fat percentage and the FMI was elevated above the recommended cutoff in $19.2 \%$ patients (Table 1 ).

\section{2) Metabolic Syndrome}

Of 130 patients, 114 patients had all the 5 parameters available for the detection of metabolic syndrome (Table 2). Thirty patients (26.3\%) satisfied the criteria for metabolic syndrome as per the consensus definition for Asian Indians. Of these, 51 patients $(44.7 \%)$ had abdominal obesity evidenced by waist circumference above the cutoff for metabolic syndrome. Fasting hyperglycemia (FBS > $100 \mathrm{mg} / \mathrm{dL}$ ) was present in 40 patients (35.1\%). Mean HDL was below the recommended cut- off value for MS in 58 patients ( $50.9 \%$ ). Fasting hypertriglyceridemia (TG $>150 \mathrm{mg} / \mathrm{dL}$ ) was noted in 16 patients (14.0\%) while hypertension was noted in 6 patients (5.3\%).

\section{3) Fatty Liver}

On FibroScan, mean liver stiffness measurement was $4.9 \pm 1.2$ $\mathrm{kPa}$ and mean CAP was $226.7 \pm 50.2 \mathrm{~dB}$. Twenty-three percent of patients had fatty liver (CAP $\geq 263 \mathrm{~dB}$ ) with $11.5 \%, 3.8 \%$, and $7.7 \%$ patients having grade I, grade II and grade III fatty liver, respectively.

\section{DISCUSSION}

Contrary to the popular belief, the present study shows a relatively high prevalence of metabolic syndrome in treatment naïve patients with $\mathrm{CeD}$. Of 44 treatment naïve patients with $\mathrm{CeD}, 5$ (11.4\%) had metabolic syndrome at the baseline. There was a further rise in the prevalence of metabolic syndrome with 9 of 44 patients (18.2\%) having features of metabolic syndrome 1 year after the institution of GFD. Furthermore, in patients who were on GFD for more than 1 year, the prevalence of metabolic syndrome was even higher with 30 of 114 patients (26.3\%) having metabolic syndrome, similar to that in the general population. ${ }^{24,25}$ The higher prevalence of metabolic syndrome in treatment naivve patients with $\mathrm{CeD}$ patients in the present study compared to an earlier study by Tortora et al. ( $11 \%$ vs. $2 \%$ ), ${ }^{9}$ could be related to the difference in the definition of metabolic syndrome (consensus definition for Asian Indians in the present study vs. Adult Treatment Panel III criteria used by Tortora, et al.)

Furthermore, present study demonstrated a significant increase in the prevalence of fatty liver from 14.3\%, as demonstrated on FibroScan, at the time of diagnosis of CeD, to 29.5\% 1 year of GFD $(P=0.002)$. The prevalence of fatty liver in those patients with $\mathrm{CeD}$ who were following on GFD for more than 1 year was $23 \%$, which is similar to the population prevalence of the fatty liver disease varying from $16 \%$ to $32 \%$ in India. ${ }^{26-28}$ The results of the present study show a higher prevalence of fatty liver than that reported in an earlier study. ${ }^{18}$ The higher prevalence of fatty liver in these patients may partly be because of use of a more sensitive and more reliable technique such as FibroScan for detection of fatty liver in comparison to ultrasonographic examination, which is mostly qualitative, subjective and operator dependent and more likely to miss the lower degrees of fat accumulation in the liver. ${ }^{29}$

While $13 \%$ patients had a BMI in overweight/obese category at the diagnosis of $\mathrm{CeD}$, the proportion increased to ap- 
proximately $25 \%$ after 1 year of GFD in them. Overall $89 \%$ of patients gained weight across different BMI categories after initiation of GFD. Interestingly, the increase in the BMI was mainly in the body fat rather than in the muscle mass, as suggested by the rise is the body fat percent and FMI in them.

The development of metabolic syndrome, obesity, and fatty liver is a slow process and all the metabolic abnormalities and their severity increase with increasing duration. The occurrence of metabolic syndrome and fatty liver in patients with CeD, which otherwise is a malabsorptive state, is an important observation and such a disease have long-term adverse consequences. It calls for our attention because it is still believed that patients with $\mathrm{CeD}$ are undernourished and overweight/ obesity is not a concern in them. Furthermore, GFD is the only available treatment for $\mathrm{CeD}$ at this point of time, and a longterm GFD can lead to perpetual and progressive worsening of metabolic derangements with increasing duration of GFD and thus predisposing them to higher cardiovascular risk. Therefore, it is imperative that we recognize metabolic abnormalities as a reality in patients with $\mathrm{CeD}$ and hence initiate appropriate preventive strategies, including counselling for physical activities and a well-balanced GFD. It is also relevant to advocate to the health authorities to legislate and monitor the calories and fat contents of gluten-free food items.

While the strength of the present study includes inclusion of not only the patients with $\mathrm{CeD}$ and their follow-up at 1 year but also the inclusion of a relatively large number of patients with $\mathrm{CeD}$ who were already on GFD for more than 1 year. There are however few shortcomings of the present study. The follow-up of patients was only for 1 year and a longer followup would have highlighted the longer-term adverse consequences in these patients. While these patients were counseled by a trained CeD dietician, we could not collect systematically the daily calories and nutrition intake and energy expenditure data in them which could have helped further substantiate if GFD was directly related to the development of the metabolic derangements in this subset of patients.

In conclusion, patients with $\mathrm{CeD}$ are at high risk of developing metabolic syndrome and fatty liver with the initiation of GFD. Patients with CeD on GFD should be assessed for nutritional and metabolic features at regular interval. They should be advised to avoid adding excess fats and sugars to the homemade gluten-free products and avoid taking commercially available GFD with high fats and sugars like cakes, cookies, sweets and biscuits. They should be counseled about a balanced diet and physical activity.

\section{ADDITIONAL INFORMATION}

\section{Funding Source}

The authors received no financial support for the research, authorship, and/or publication of this article.

\section{Conflict of Interest}

No potential conflict of interest relevant to this article was reported.

\section{Author Contribution}

Conceptualization: Makharia GK, Agarwal A. Methodology: Agarwal A, Makharia GK, Singh A, Mehtab W. Formal analysis: Agarwal A, Makharia GK, Chauhan A. Project administration: Makharia GK. Visualization: Makharia GK, Agarwal A. Writing - original draft: Agarwal A, Singh A, Chauhan A, Rajput MS. Writing - review and editing: Agarwal A, Makharia GK, Ahuja V, Makharia GK, Singh N, Mehtab W, Gupta V. Approval of final manuscript: all authors.

\section{Others}

We acknowledge our patients for participation in the study and the staff and residents of the Celiac Disease Clinic, All India Institute of Medical Sciences.

\section{ORCID}

Agarwal A

Singh A

Mehtab W

Gupta V

Chauhan A

Rajput MS

Singh N

Ahuja $\mathrm{V}$

https://orcid.org/0000-0002-9729-891X https://orcid.org/0000-0002-3317-8038 https://orcid.org/0000-0002-4320-763X https://orcid.org/0000-0002-9620-1696 https://orcid.org/0000-0002-1305-189X https://orcid.org/0000-0002-1421-3440 https://orcid.org/0000-0002-8912-2949 https://orcid.org/0000-0002-1577-0118

Makharia GK

\section{REFERENCES}

1. Singh I, Agnihotri A, Sharma A, et al. Patients with celiac disease may have normal weight or may even be overweight. Indian J Gastroenterol 2016;35:20-24.

2. Tucker E, Rostami K, Prabhakaran S, Al Dulaimi D. Patients with coeliac disease are increasingly overweight or obese on presentation. J Gastrointestin Liver Dis 2012;21:11-15.

3. Stein AC, Liao C, Paski S, Polonsky T, Semrad CE, Kupfer SS. Obesity and cardiovascular risk in adults with celiac disease. J 
Clin Gastroenterol 2016;50:545-550.

4. Kabbani TA, Goldberg A, Kelly CP, et al. Body mass index and the risk of obesity in coeliac disease treated with the glutenfree diet. Aliment Pharmacol Ther 2012;35:723-729.

5. Ukkola A, Mäki M, Kurppa K, et al. Changes in body mass index on a gluten-free diet in coeliac disease: a nationwide study. Eur J Intern Med 2012;23:384-388.

6. Cheng J, Brar PS, Lee AR, Green PH. Body mass index in celiac disease: beneficial effect of a gluten-free diet. J Clin Gastroenterol 2010;44:267-271.

7. Dickey W, Kearney N. Overweight in celiac disease: prevalence, clinical characteristics, and effect of a gluten-free diet. Am J Gastroenterol 2006;101:2356-2359.

8. Reilly NR, Aguilar K, Hassid BG, et al. Celiac disease in normal-weight and overweight children: clinical features and growth outcomes following a gluten-free diet. J Pediatr Gastroenterol Nutr 2011;53:528-531.

9. Tortora R, Capone P, De Stefano G, et al. Metabolic syndrome in patients with coeliac disease on a gluten-free diet. Aliment Pharmacol Ther 2015;41:352-359.

10. Diamanti A, Capriati T, Basso MS, et al. Celiac disease and overweight in children: an update. Nutrients 2014;6:207-220.

11. Papastamataki M, Papassotiriou I, Bartzeliotou A, et al. Incretins, amylin and other gut-brain axis hormones in children with coeliac disease. Eur J Clin Invest 2014;44:74-82.

12. Dam-Larsen S, Becker U, Franzmann MB, Larsen K, Christoffersen P, Bendtsen F. Final results of a long-term, clinical followup in fatty liver patients. Scand J Gastroenterol 2009;44:12361243.

13. Naschitz JE, Yeshurun D, Zuckerman E, Arad E, Boss JH. Massive hepatic steatosis complicating adult celiac disease: report of a case and review of the literature. Am J Gastroenterol 1987;82:1186-1189.

14. Bardella MT, Valenti L, Pagliari C, et al. Searching for coeliac disease in patients with non-alcoholic fatty liver disease. Dig Liver Dis 2004;36:333-336.

15. Lo Iacono O, Petta S, Venezia G, et al. Anti-tissue transglutaminase antibodies in patients with abnormal liver tests: is it always coeliac disease? Am J Gastroenterol 2005;100:2472-2477.

16. Rahimi AR, Daryani NE, Ghofrani $\mathrm{H}$, et al. The prevalence of celiac disease among patients with non-alcoholic fatty liver disease in Iran. Turk J Gastroenterol 2011;22:300-304.

17. Reilly NR, Lebwohl B, Hultcrantz R, Green PH, Ludvigsson JF. Increased risk of non-alcoholic fatty liver disease after diagno- sis of celiac disease. J Hepatol 2015;62:1405-1411.

18. Tovoli F, Negrini G, Farì R, et al. Increased risk of nonalcoholic fatty liver disease in patients with coeliac disease on a glutenfree diet: beyond traditional metabolic factors. Aliment Pharmacol Ther 2018;48:538-546.

19. Emilsson L, Lebwohl B, Sundström J, Ludvigsson JF. Cardiovascular disease in patients with coeliac disease: a systematic review and meta-analysis. Dig Liver Dis 2015;47:847-852.

20. Husby S, Koletzko S, Korponay-Szabó IR, et al. European Society for Pediatric Gastroenterology, Hepatology, and Nutrition guidelines for the diagnosis of coeliac disease. J Pediatr Gastroenterol Nutr 2012;54:136-160.

21. World Health Organization. STEPwise approach to surveillance (STEPS) [Internet]. c2018 [cited 2018 Jul 10]. http:// www.who.int/ncds/surveillance/steps/en/.

22. Misra A, Chowbey P, Makkar BM, et al. Consensus statement for diagnosis of obesity, abdominal obesity and the metabolic syndrome for Asian Indians and recommendations for physical activity, medical and surgical management. J Assoc Physicians India 2009;57:163-170.

23. Rout G, Kedia S, Nayak B, et al. Controlled attenuation parameter for assessment of hepatic steatosis in Indian patients. J Clin Exp Hepatol 2019;9:13-21.

24. Sawant A, Mankeshwar R, Shah S, et al. Prevalence of metabolic syndrome in urban India. Cholesterol 2011;2011:920983.

25. Gupta R, Deedwania PC, Gupta A, Rastogi S, Panwar RB, Kothari K. Prevalence of metabolic syndrome in an Indian urban population. Int J Cardiol 2004;97:257-261.

26. Singh SP, Nayak S, Swain M, et al. Prevalence of nonalcoholic fatty liver disease in coastal eastern India: a preliminary ultrasonographic survey. Trop Gastroenterol 2004;25:76-79.

27. Amarapurkar D, Kamani P, Patel N, et al. Prevalence of non-alcoholic fatty liver disease: population based study. Ann Hepatol 2007;6:161-163.

28. Mohan V, Farooq S, Deepa M, Ravikumar R, Pitchumoni CS. Prevalence of non-alcoholic fatty liver disease in urban south Indians in relation to different grades of glucose intolerance and metabolic syndrome. Diabetes Res Clin Pract 2009;84:84-91.

29. Macabuag-Oliva AM, Capellan ML, Benitez B. A comparison of the sensitivity and specificity of ultrasound elastography compared to liver ultrasound, ALT, and AST in the detection of fatty liver and fibrosis in patients with metabolic syndrome and type 2 diabetes mellitus. J ASEAN Fed Endocr Soc 2014; 29:59-64. 